\title{
The Effect of Iodine Status on the Risk of Thyroid Nodules: A Cross-Sectional Study in Zhejiang, China
}

\author{
Xiaoming Lou, Xiaofeng Wang, Zhifang Wang, Guangming Mao, Wenming Zhu, \\ Yuanyang Wang, Xuejiao Pan, Zhijian Chen, and Zhe Mo

\begin{abstract}
Department of Environmental Health, Zhejiang Provincial Center for Disease Prevention and Control, 3399 Binsheng Road, Hangzhou 310051, Zhejiang, China
\end{abstract} \\ Correspondence should be addressed to Zhe Mo; zhmo@cdc.zj.cn
}

Received 14 May 2020; Revised 9 July 2020; Accepted 5 August 2020; Published 18 August 2020

Academic Editor: Alexander Schreiber

Copyright ( $) 2020$ Xiaoming Lou et al. This is an open access article distributed under the Creative Commons Attribution License, which permits unrestricted use, distribution, and reproduction in any medium, provided the original work is properly cited.

Objective. The aim of this study was to explore whether iodine nutrition is associated with the risk of thyroid nodules among adult population in Zhejiang Province, China. Methods. A cross-sectional study was conducted in the general population aged 18 years or older. A total of 2,710 subjects received physical examination, questionnaires, and thyroid ultrasonography. Urinary iodine concentration (UIC) and thyroid hormone levels were measured and documented for each subject. 4 multiple logistic regression models adjusted for other risk factors were applied to analyze the association between iodine nutrition and thyroid nodules. Results. The prevalence of thyroid nodules was $15.5 \%$ among all adults. As indicated by all 4 models, subjects with UIC varying from $200 \mu \mathrm{gl}^{-1}$ to $399 \mu \mathrm{g} \mathrm{l} \mathrm{I}^{-1}$ had lower risk of thyroid nodules compared with those with relatively low UIC $\left(<100 \mu \mathrm{g} l^{-1}\right)$, with approximately 37-57 percent reduction in risk. Moreover, subjects with UIC between 100 and $199 \mu \mathrm{g}{ }^{-1}$ had a decreased risk of thyroid nodules in model 1 and $2(\mathrm{OR}=0.75,95 \% \mathrm{CI}, 0.58-0.97 ; \mathrm{OR}=0.75,95 \% \mathrm{CI}, 0.58-0.97$, respectively). However, there was no significant difference of risk in thyroid nodules between subjects with high UIC $\left(\geq 400 \mu \mathrm{g} 1^{-1}\right)$ and low UIC $\left(<100 \mu \mathrm{gl} 1^{-1}\right)$. Furthermore, intake of iodized salt was inversely associated with risk of thyroid nodules, with approximately 69-77 percent reduction in risk. Conclusion. The relationship between UIC and the risk of thyroid nodules is U-shaped. Consumption of noniodized salt is an independent risk factor of thyroid nodules.

\section{Introduction}

The thyroid nodules are a discrete lesion within the thyroid gland that is radiologically distinct from the surrounding thyroid parenchyma [1]. Thyroid nodules are a common clinical thyroid disease [2]. Epidemiologic studies have shown that the prevalence of thyroid nodules was approximately $4 \%-$ $7 \%$ as determined by palpation [3]. Meanwhile, the prevalence of thyroid nodules was $19 \%-67 \%$ on high-resolution ultrasound [4]. Approximately $7 \%-15 \%$ of thyroid nodules are malignant [3,5]. Some environmental factors, such as age, iodine intake, gender, lifestyle, and radiation history of the head and neck, could affect the risk of thyroid nodules [6-8]. Iodine is an essential element required for the synthesis of thyroid hormones, thyroxine and triiodothyronine. Thyroid hormone disorders could be induced due to both insufficient and excessive iodine intakes. Some studies revealed that low iodine intake could increase the risk of thyroid nodules $[9,10]$. On the other hand, a few studies have shown that excessive iodine intake may also lead to development of thyroid nodules. Whether excessive iodine intake is involved in the increase of thyroid nodules occurrence remains unclear. The aim of this study was to explore whether iodine nutrition is associated with the risk of thyroid nodules and to investigate the effects of salt iodine on the prevalence of thyroid nodules among adults.

\section{Methods}

2.1. Subjects. This study was conducted in Zhejiang Province, which is located on the east China coast. The recruit strategy of study participants was performed as follows. 
Firstly, one district and one county were selected randomly from Zhejiang Province. Secondly, two subdistricts or towns were selected randomly from each selected district or county. Thirdly, residents of these subdistricts or towns were recruited based on age and gender ratio of the population census in 2010 [11]. Finally, our study included 2,710 participants, of which 1,395 were from the district and 1,315 were from the county. The main inclusions were participants who aged $\geq 18$ years and lived for $\geq 5$ years at local residence. The exclusion criteria were participants who received contrast-enhanced ultrasonography with iodine-containing contrast agent, or those who have taken the drug of ethylamiodarone in the past three months, or those who were pregnant. Our study was conducted from December 2015 through July 2016. Ethical approval was obtained from the ethics committee of the Zhejiang Provincial Centre for Disease Prevention and Control, and all participants have provided written informed consent.

2.2. Lifestyle and Examination Data. The subjects completed questionnaires regarding lifestyle and iodine nutrition information through face-to-face interviews by well-trained investigators. Demographic characteristics, iodine nutrition status, personal and family history of thyroid disease, general medical history, and smoking status of interviewees were documented. Furthermore, information about types of salt used in households, including iodized salt or noniodized salt, was collected. The quality of questionnaire completion was checked daily. If blank entries were found, we would further gather the missing information through phone interviews. Additionally, anthropometric and physical examinations were also performed by professional public health doctors. BMI was calculated as weight $(\mathrm{kg}) /$ height $(\mathrm{m})^{2}$. Thyroid status was examined to detect thyroid nodules by portable ultrasound machine (GE, LOGIQ $\alpha 100$, Boston, MA, USA) with a $7.5-\mathrm{MHZ}, 60-\mathrm{mm}$ transducer.

\subsection{Iodine Concentration and Biochemistry Data. Each} participant provided $5 \mathrm{~mL}$ spot urine and $10 \mathrm{~mL}$ venous blood sample, which were immediately placed at $-20^{\circ} \mathrm{C}$ before being sent to the laboratory for further analysis. Urinary iodine concentration (UIC) was measured using the spectrophotometer method (WS/T 107-2006) [12]. We applied the reference material (GBW09108, GBW9109, and GBW9110) from the Centre for Disease Control (CDC) for China for quality control. The values of the reference materials were $70.8 \pm 9.0 \mu \mathrm{gl}^{-1}, \quad 143 \pm 10 \mu \mathrm{gl}^{-1}$, and $224 \pm 14 \mu \mathrm{gl}^{-1}$, with an interassay CV of $2.3 \%, 2.5 \%$, and $2.4 \%$, and an intra-assay $\mathrm{CV}$ of $2.7 \%, 1.4 \%$, and $2.3 \%$, respectively. According to the recommended iodine nutrition status evaluation criteria of the WHO [13], iodine deficiency was indicated by median urinary iodine $(\mathrm{MUI})<100 \mu \mathrm{gl}^{-1}$, adequate iodine nutrition by $100 \mu \mathrm{gl}^{-1} \leq \mathrm{MUI} \leq 199 \mu \mathrm{gl} \mathrm{l}^{-1}$, above requirements by $200 \mu \mathrm{gl}^{-1} \leq \mathrm{MUI} \leq 299 \mu \mathrm{gl}^{-1}$, and excessive by MUI $\geq 300 \mu \mathrm{gl}^{-1}$.

Serum levels of thyroid-stimulating hormone (TSH), thyroid peroxidase antibody (TPOAb), and thyroglobulin antibody were measured for each subject by using the immunochemiluminescent method from a Cobas 601 analyzer (Roche Diagnostic, Switzerland). Free thyroxine (FT4) and free triiodothyronine (FT3) levels were measured only if TSH was outside the reference range $\left(0.27-4.2 \mathrm{mIU} \mathrm{l}^{-1}\right)$. The repeatability of serum assays of TSH, FT4, FT3, TPOAb, and TGAb was ensured by intra-assay coefficients of variation (CV) of $1.1 \%-6.3 \%$ and interassay CV of $1.9 \%-9.5 \%$ [14]. The thyroid functional status for each participant was identified based on the diagnostic criteria for thyroid disorders [14].

Fasting blood glucose (FBG), blood glucose after 2 hour, 75-gram oral glucose tolerance test (OGTT-2h), triglyceride (TG), total cholesterol (TC), low-density lipoprotein cholesterol (LDL-C), high-density lipoprotein cholesterol (HDL-C), and uric acid (UA) were determined for all participants by using an automatic chemistry analyzer (Mindray, BS-180, Shenzhen, China), and hemoglobin A1c (HbAlc) was measured by an HbA1c analyzer (Bio-Rad, VARIANT II Hemoglobin Analyzer, CA, USA). The measuring methods were reported in detail previously [15].

2.4. Statistical Analysis. We used the statistical analysis system (SAS) software (version 9.4, Cary, NC, USA) for statistical analysis. Continuous variables which were normally distributed according to the Shapiro-Wilk test and categorical variables were described as mean (SD) and percentages, respectively. The $t$-test and chi-square test were applied to test the difference between subjects with and without thyroid nodules in terms of categorical and continuous variables. Other continuous variables that were not normally distributed were presented as median (interquartile range (IQR)), and we used Wilcoxon test to assess the differences in those.

We further examined the nonlinear or linear associations between UIC and the prevalence of thyroid nodules as follows. Firstly, UIC was cut into ten groups according to decile. Secondly, we calculated the MUI of each group as exposure and the prevalence of thyroid nodules of each group as response. Finally, the quadratic, linear, and spline fitted GLM models were fitted to examine the associations. To exhibit the relationship more clearly, we generated expose-response curves to visualize the effects of UIC on the prevalence of thyroid nodules.

Logistic regression models were used to estimate the effect of UIC, and types of salt on thyroid nodules were stratified by gender. In order to reduce confounders, we only included these variables which have significant effect on the risk of thyroid nodules according to the result of univariate analysis. The base statistical mode (model 1) was adjusted for demographic characteristics including gender (male vs. female), age (year, continuously), education (illiteracy/primary school, junior middle school, high school/technical secondary school, and university above), and profession (physical labor, agricultural labor, mental labor, and others). The associations were assessed by three additional models (model 2, 3, and 4). Model 2 additionally corrected for hypertension (yes vs. no) based on model 1. In model 3, some physical examination and biochemistry variables, such 
as BMI ( $\mathrm{mg} \mathrm{dl}{ }^{-1}$,continuously), waist circumference $(\mathrm{cm}$, continuously), FBG (mmol $\mathrm{l}^{-1}$, continuously), OTGG-2h (mmol l$~^{-1}$, continuously), HbAlc (year, continuously), TC (mmol $\mathrm{l}^{-1}$,continuously), LDL-C (mmol $\mathrm{l}^{-1}$,continuously), and UA (mmol l-1, continuously), were included as covariates in addition to confounding factors in model 2. Model 4 further adjusted thyroid hormone including TSH ( $\mathrm{mIU}^{-1}$, continuously) and TGAb (IU $1^{-1}$, continuously). The linear combination was used to calculate the estimates for different genders [16]. Results are expressed as odds ratio (OR) and 95\% confidence interval (95\% CI).

\section{Results}

The prevalence of thyroid nodules and MUI was 15.5\% (420/ 2710 ) and 158.0 (134.2) $\mu \mathrm{gl}^{-1}$ among all adults, respectively. The MUIs of subjects with and without thyroid nodules were $122.9(110.3) \mu \mathrm{gl}^{-1}$ and $164.0(134.6) \mu \mathrm{gl}^{-1}$, respectively, and subjects with thyroid nodules had lower MUI than subjects without thyroid nodules $(p<0.01)$. The correlation coefficient between the reported salt intake with the corresponding UIC is 0.4 with a significant $p$ value $(p<0.01)$.

Subjects who belong to the category of female, older, low educational level, agricultural worker, hypertensive patients, consumed noniodized salt, and low UIC had a higher prevalence of thyroid nodules $(p<0.01)$. Compared with subjects without thyroid nodules, those with thyroid nodules reported a significantly higher level of BMI and waist circumference and higher values of FBG, OTGG-2h, HbA1c, TC, LDL, and TGAb, as well as lower values of UA and TSH. Meanwhile, we found no significant differences between participants with and without thyroid nodules in terms of income, region, smoke, passive smoke, family history of thyroid diseases, heart rate, TG, HDL, thyroid functional status, and TPOAb (Table 1). From Table 1, we could see that the prevalence of thyroid nodules gradually increased with age $(p<0.01)$.

Significant quadratic, spline, and linear associations were discovered between UIC and the prevalence of thyroid nodules, respectively $(p<0.01)$. Moreover, larger adjusted $R$ squares were observed in quadratic and spline fitted GLM models than that in the linear model. From Figure 1, we could find the highest prevalence of thyroid nodules in the low-UIC group. Given the results, the iodine deficiency group (low UIC) was defined as reference in the logistic regression model. Meanwhile, to investigate the effect of excessive UIC on thyroid nodules, excessive UIC was subdivided into 300-399, 400-499, and $\geq 500 \mu \mathrm{gl}^{-1}$ groups. Next, we would fit two series multiple logistic models with effects of UIC on thyroid nodules, one of which classified UIC according to the iodine nutritional status evaluation criteria of the WHO (Table 2), and the other of which adopted the UIC as 6 groups with subdivided excessive UIC $\left(\geq 300 \mu \mathrm{gl}^{-1}\right)$ into $300-399,400-499$, and $\geq 500 \mu \mathrm{gl}^{-1}$ groups (Table 3).

Tables 2 and 3 present the results of the four multiple logistic models regarding the association between UIC and thyroid nodules as ORs, $95 \%$ CIs, and $p$ values. For all adults, subjects with UIC varying from $200 \mu \mathrm{gl}^{-1}$ to $399 \mu \mathrm{gl}^{-1}$ had a lower risk of thyroid nodules compared with those with low UIC $\left(<100 \mu \mathrm{gl}^{-1}\right)$ in all four models, with approximately 37-57 percent reduction in risk. Moreover, subjects with UIC between $100 \mu \mathrm{gl}^{-1}$ and $199 \mu \mathrm{g}{ }^{-1}$ had a decreased risk of thyroid nodules in model 1 and $2(\mathrm{OR}=0.75,95 \% \mathrm{CI}$, 0.58-0.97; OR $=0.75,95 \%$ CI, 0.58-0.97, respectively). However, there was no significant difference regarding risk in thyroid nodules between subjects with high UIC $\left(\geq 400 \mu \mathrm{gl}^{-1}\right)$ and low UIC $\left(<100 \mu \mathrm{gl}^{-1}\right)$ in all four models. Separate analysis was performed stratified by gender. Similar associations were observed in the female group. Males with UIC between $200 \mu \mathrm{gl}^{-1}$ and $299 \mu \mathrm{gl}^{-1}$ had an inverse association with risk of thyroid nodules in model 1 and 2 $(\mathrm{OR}=0.55,95 \% \mathrm{CI}, 0.34-0.91 ; \mathrm{OR}=0.55,95 \% \mathrm{CI}, 0.34-0.91$, respectively).

Furthermore, intake of iodized salt was inversely associated with risk of thyroid nodules in all four models, with approximately 69-77 percent reduction in risk. Similar associations were observed in male and female groups (Table 4).

\section{Discussion}

In this study, significant association was observed between iodine nutrition and thyroid nodules among 2,710 participants in Zhejiang Province, China. We found that adults who had a low or high UIC or with consumption of noniodized salt had a higher risk of thyroid nodules, suggesting that adequate iodine nutrition may decrease the risk of thyroid nodules.

The prevalence of thyroid nodules in adults of Zhejiang Province was $15.5 \%$. It is slightly lower than that of mainland China (22.8\%) [17], France (34.7\%) [18], and Germany (23.4\%) [19]. Moreover, it is partly in line with that in Korea (13.4\%) [20] and Brazil (17.0\%) [21]. Many epidemiological studies [22-24] have presented that the prevalence of thyroid nodules increases with age. The mechanism may be that the thyroid will undergo degenerative changes with age, resulting in development of nodules [24].

In our study, we found that the relationship of UIC and the risk of thyroid nodules presented a U-shaped curve with an increase in risk from both low- and high-iodine intake levels in both univariate and multivariate models. It was consistent with other studies [25-27]. Iodine deficiency could contribute to elevating the risk of thyroid nodules; several mechanisms may be involved in this association. Firstly, iodine deficiency leads to the increase of TSH due to the feedback regulation of the hypothalamus-pituitarythyroid axis. After a period of time, thyroid follicular cell compensatory hyperplasia and hypertrophy form nodules [23]. Secondly, previous studies found that iodine deficiency could cause the formatting thyroid nodules by generating autonomous thyrocyte cluster via the promotion of thyrocyte cell growth and DNA mutagenesis [28]. Moreover, it is well known that iodized salt is the main contribution to dietary iodine intake [29]. According to previous studies [29], the dietary iodine intake from iodized salt was $250.03 \mu \mathrm{g} \mathrm{d}^{-1}$, which accounted for $73.45 \%$ of total dietary iodine indicating that subjects would lose $73.45 \%$ of dietary 
TABLE 1: Summary statistics of variables between nonthyroid nodule and thyroid nodule groups.

\begin{tabular}{|c|c|c|c|c|}
\hline Variables & Nonthyroid nodule $(n=2290)$ & Thyroid nodule $(n=420)$ & Total $(n=2710)$ & $p$ \\
\hline Gender $^{\mathrm{a}}$ & & & & 0.00 \\
\hline Female & $1108(81.7)$ & $249(18.4)$ & $1357(50.1)$ & \\
\hline Male & $1182(87.4)$ & $171(12.6)$ & $1353(49.9)$ & \\
\hline Age $\left(\right.$ year $\left.^{\mathrm{b}}\right)$ & $42.40(15.8)$ & $50.09(15.5)$ & $43.0(25.0)$ & 0.00 \\
\hline Age group ${ }^{a}$ & & & & 0.00 \\
\hline $18-29$ & $608(91.8)$ & $54(8.2)$ & $662(24.4)$ & \\
\hline $30-39$ & $478(88.4)$ & $63(11.7)$ & $541(20.0)$ & \\
\hline $40-49$ & $487(85.0)$ & $86(15.0)$ & $573(21.1)$ & \\
\hline $50-59$ & $340(79.1)$ & $90(20.9)$ & $430(15.9)$ & \\
\hline $60-69$ & $223(75.1)$ & $74(24.9)$ & $297(11.0)$ & \\
\hline$\geq 70$ & $154(74.4)$ & $53(25.6)$ & $207(7.6)$ & \\
\hline \multicolumn{5}{|l|}{ Education $^{\mathrm{a}}$} \\
\hline Illiteracy/primary school & $521(79.4)$ & $135(20.6)$ & $656(24.2)$ & \\
\hline Junior middle school & $687(83.5)$ & $136(16.5)$ & $823(30.4)$ & \\
\hline High school/technical secondary school & $476(87.8)$ & $66(12.2)$ & $542(20.0)$ & \\
\hline University/college/graduate student & $606(88.0)$ & $83(12.0)$ & $689(25.4)$ & \\
\hline Profession $^{\text {a }}$ & & & & 0.00 \\
\hline Physical labor & $932(84.4)$ & $172(15.6)$ & $1104(40.7)$ & \\
\hline Agricultural labor & $275(76.0)$ & $87(24.0)$ & $362(13.4)$ & \\
\hline Mental labor & $694(88.5)$ & $90(11.5)$ & $784(28.9)$ & \\
\hline Others & $389(84.6)$ & $71(15.4)$ & $460(17.0)$ & \\
\hline Income, thousand yuan ${ }^{\mathrm{a}}$ & & & & 0.06 \\
\hline$<10$ & $252(88.1)$ & $34(11.9)$ & $286(10.6)$ & \\
\hline $10-29$ & $367(82.8)$ & $76(17.2)$ & $443(16.4)$ & \\
\hline $30-49$ & $626(82.0)$ & $137(18.0)$ & $763(28.2)$ & \\
\hline $50-99$ & $636(85.6)$ & $107(14.4)$ & $743(27.4)$ & \\
\hline$\geq 100$ & $409(86.1)$ & $66(13.9)$ & $475(17.5)$ & \\
\hline Region $^{\mathrm{a}}$ & & & & 0.41 \\
\hline County & $1119(85.1)$ & $196(14.9)$ & $1315(48.5)$ & \\
\hline District & $1171(83.9)$ & $224(16.1)$ & $1395(51.5)$ & \\
\hline Smoke ${ }^{\mathrm{a}}$ & & & & 0.94 \\
\hline No & $1874(84.5)$ & $343(15.5)$ & $2217(81.8)$ & \\
\hline Yes & $416(84.4)$ & $77(15.6)$ & $493(18.2)$ & \\
\hline Passive smoke $^{\mathrm{a}}$ & & & & 0.82 \\
\hline No & $1648(84.6)$ & $300(15.4)$ & $1948(71.9)$ & \\
\hline Yes & $642(84.3)$ & $120(15.7)$ & $762(28.1)$ & \\
\hline Family history of thyroid diseases ${ }^{a}$ & & & & 0.60 \\
\hline No & $2194(84.6)$ & $400(15.4)$ & $2594(95.7)$ & \\
\hline Yes & $96(82.8)$ & $20(17.2)$ & $116(4.3)$ & \\
\hline Hypertension $^{\mathrm{a}}$ & & & & 0.00 \\
\hline No & $1724(86.1)$ & $278(13.9)$ & $2002(73.9)$ & \\
\hline Yes & $566(79.9)$ & $142(20.1)$ & $708(26.1)$ & \\
\hline BMI $\left(\mathrm{kg} / \mathrm{m}^{2 \mathrm{~b}}\right)$ & $23.4(3.4)$ & $24.2(3.2)$ & $23.6 \pm 3.4$ & 0.00 \\
\hline Waist circumference $\left(\mathrm{cm}^{\mathrm{b}}\right)$ & $80.8(9.5)$ & $84.7(8.8)$ & $81.4 \pm 9.5$ & 0.00 \\
\hline Heart rate (times/minute ${ }^{b}$ ) & $79.7(11.7)$ & $80.2(11.2)$ & $79.8 \pm 11.6$ & 0.41 \\
\hline $\mathrm{FBG}\left(\mathrm{mmol} \mathrm{l}^{-1 \mathrm{~b}}\right)$ & $5.5(1.5)$ & $5.7(1.3)$ & $5.5 \pm 1.5$ & 0.00 \\
\hline OGTT-2h $\left(\mathrm{mmol} \mathrm{l}^{-1 \mathrm{~b}}\right)$ & $5.9(2.2)$ & $6.3(2.4)$ & $5.9 \pm 2.2$ & 0.00 \\
\hline $\mathrm{HbAlc} \mathrm{c}^{\mathrm{b}}$ & $5.4(1.1)$ & $5.6(0.8)$ & $5.5 \pm 1.0$ & 0.00 \\
\hline $\mathrm{TG}\left(\mathrm{mmol} \mathrm{l} \mathrm{l}^{-1 \mathrm{~b}}\right)$ & $1.6(2.9)$ & $1.6(1.4)$ & $1.6 \pm 2.7$ & 0.96 \\
\hline $\mathrm{TC}\left(\mathrm{mmol} \mathrm{l} \mathrm{l}^{-1 \mathrm{~b}}\right)$ & $4.6(1.3)$ & $5.0(1.1)$ & $4.7 \pm 1.3$ & 0.00 \\
\hline LDL-C $\left(\mathrm{mmol} \mathrm{l}^{-1 \mathrm{~b}}\right)$ & $2.8(0.8)$ & $3.1(0.9)$ & $2.9 \pm 0.8$ & 0.00 \\
\hline $\mathrm{HDL}-\mathrm{C}(\mathrm{mmol} \mathrm{l})^{-1 \mathrm{~b}}$ & $1.6(0.5)$ & $1.6(0.4)$ & $1.6 \pm 0.5$ & 0.32 \\
\hline $\mathrm{UA}\left(\mathrm{mmol} \mathrm{l} \mathrm{l}^{-1 \mathrm{~b}}\right)$ & $297.1(169.8)$ & $285.1(84.7)$ & $295.2 \pm 159.7$ & 0.03 \\
\hline TSH $\left(\mathrm{mIU} \mathrm{l}^{-1 \mathrm{c}}\right)$ & $2.2(1.8)$ & $2.0(1.4)$ & $2.2(1.73)$ & 0.00 \\
\hline Overt hyperthyroidism ${ }^{\mathrm{a}}$ & & & & 1.00 \\
\hline No & $2282(84.5)$ & $419(15.5)$ & $2701(99.7)$ & \\
\hline Yes & $8(88.9)$ & $1(11.1)$ & $9(0.3)$ & \\
\hline Subclinical hyperthyroidism ${ }^{a}$ & & & & 0.05 \\
\hline No & $2287(84.6)$ & $417(15.4)$ & $2704(99.8)$ & \\
\hline Yes & $3(50)$ & $3(50)$ & $6(0.2)$ & \\
\hline
\end{tabular}


TABLE 1: Continued.

\begin{tabular}{|c|c|c|c|c|}
\hline Variables & Nonthyroid nodule $(n=2290)$ & Thyroid nodule $(n=420)$ & Total $(n=2710)$ & $p$ \\
\hline Overt hypothyroidism $^{\mathrm{a}}$ & & & & 1.00 \\
\hline No & $2275(84.5)$ & $418(15.5)$ & $2693(99.4)$ & \\
\hline Yes & $15(88.2)$ & $2(11.8)$ & $17(0.6)$ & \\
\hline Subclinical hyperthyroidism ${ }^{a}$ & & & & 0.05 \\
\hline No & $1989(84.5)$ & $366(15.5)$ & $2355(86.9)$ & \\
\hline Yes & $314(88.5)$ & $41(11.5)$ & $355(13.1)$ & \\
\hline TPOAb $\left(\mathrm{IU} \mathrm{l}^{-1 \mathrm{c}}\right)$ & $11.5(5.7)$ & $11.8(5.7)$ & $11.6(5.7)$ & 0.94 \\
\hline TGAb (IU $\left.{ }^{-1 c}\right)$ & $12.5(6.7)$ & $13.2(7.3)$ & $12.6(7.0)$ & 0.00 \\
\hline Iodized salt $\mathrm{t}^{\mathrm{a}}$ & & & & 0.00 \\
\hline No & $706(71.8)$ & $277(28.2)$ & $983(36.3)$ & \\
\hline Yes & $1584(91.7)$ & $143(8.3)$ & $1727(63.7)$ & \\
\hline $\mathrm{UIC}\left(\mu \mathrm{g} \mathrm{l}^{-1 \mathrm{C}}\right)$ & $164.0(134.6)$ & $122.9(110.3)$ & $158(134.2)$ & 0.00 \\
\hline $\mathrm{UIC}\left(\mu \mathrm{g} \mathrm{l}^{-1 \mathrm{a}}\right)$ & & & & 0.00 \\
\hline$<100$ & $541(23.6)$ & $158(37.6)$ & $699(25.8)$ & \\
\hline $100-199$ & $917(40)$ & $165(39.3)$ & $1082(39.9)$ & \\
\hline $200-299$ & $530(23.1)$ & $63(15)$ & $593(21.9)$ & \\
\hline$\geq 300$ & $302(13.2)$ & $34(8.1)$ & $336(12.4)$ & \\
\hline
\end{tabular}

${ }^{a}$ Expression with the number (proportion \%), tested with the chi-square test. ${ }^{b}$ Expression with mean (SD), tested with the $t$-test. ${ }^{c}$ Expression with median (IQR), tested with the Wilcoxon method.

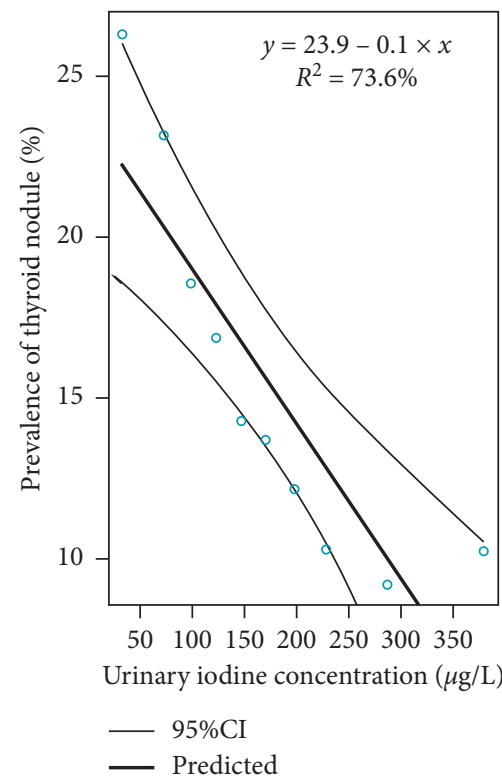

(a)

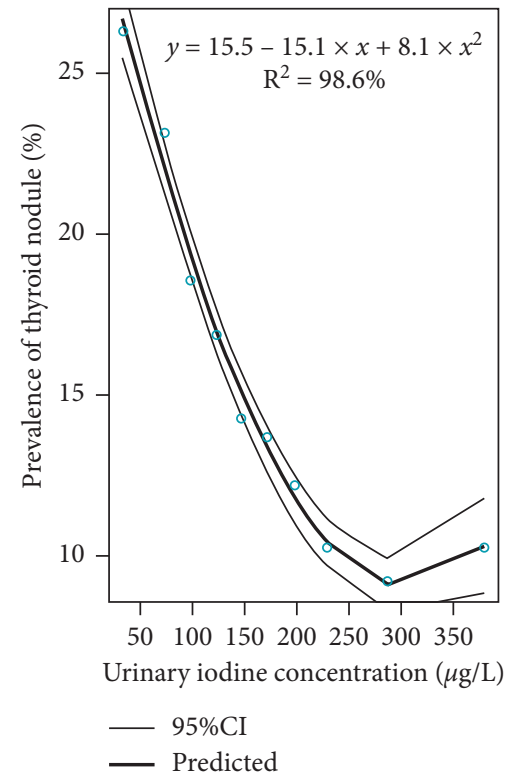

(b)

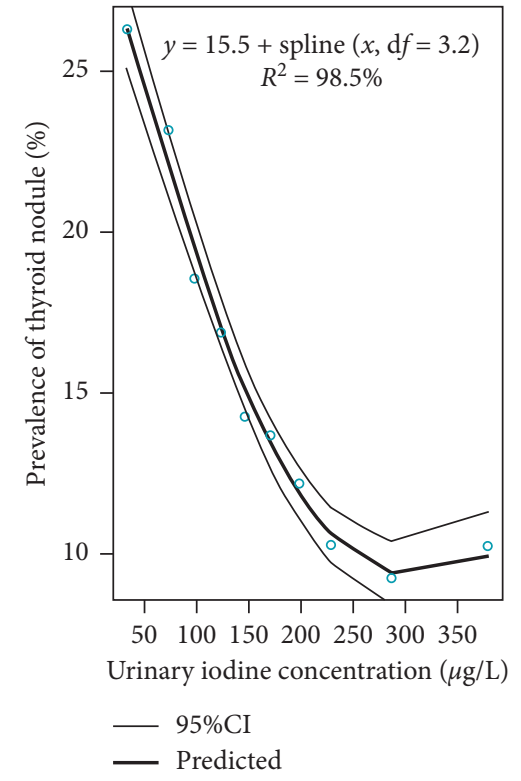

(c)

FIgURE 1: The nonlinear and linear associations between urinary iodine concentration and prevalence of thyroid nodule: (a) the linear relationship between urinary iodine concentration and prevalence of thyroid nodule was observed with adjusted $R^{2}=73.6 \%$; $(\mathrm{b})$ the quadratic curve existed between urinary iodine concentration and prevalence of thyroid nodule with adjusted $R^{2}=98.6 \%$; (c) the nonlinear relationship between urinary iodine concentration and prevalence of thyroid nodule was observed by using spline function with adjusted $R^{2}=98.5 \%$.

iodine if they consumed noniodized salt. Therefore, subjects who consumed noniodized salt could lead to a low UIC. Likewise, we also found that noniodized salt increased the risk of thyroid nodules. These results confirmed the link of noniodized salt intake-low UIC-high risk of thyroid nodules, which is consistent with previous studies [9, 23]. Furthermore, we found that $25.8 \%$ of adults had iodine deficiency although the MUI results indicated adequate iodine states. Therefore, full iodized salt exposure still remains essential for all subjects. Meanwhile, iodine deficiency may result in higher impact on female than male in part due to the reason that females were more sensitive to levels of hormones and different levels of iodine intake [30].

However, so far, there is no exact mechanism regarding excessive iodine leading to thyroid nodules [23, 30]. Meanwhile, few studies have been conducted to explore the association between excessive iodine intake and thyroid nodules. Previous studies [9, 25, 31, 32] have reported that 
TABLE 2: Effect of urinary iodine concentration on thyroid nodule according to the iodine nutritional status evaluation criteria of the WHO.

\begin{tabular}{|c|c|c|c|c|c|c|c|c|c|}
\hline \multirow{2}{*}{ Group } & \multirow{2}{*}{$\mathrm{UIC}\left(\mu \mathrm{g} \mathrm{l}^{-1}\right)$} & \multicolumn{2}{|l|}{ Model $1^{\mathrm{a}}$} & \multicolumn{2}{|l|}{ Model $2^{\mathrm{b}}$} & \multicolumn{2}{|l|}{ Model $3^{c}$} & \multicolumn{2}{|l|}{ Model $4^{\mathrm{d}}$} \\
\hline & & OR $(95 \% \mathrm{CI})$ & $p$ & OR (95\% CI) & $p$ & OR $(95 \% \mathrm{CI})$ & $p$ & OR (95\% CI) & $p$ \\
\hline \multirow{4}{*}{ All } & $<100$ & 1.00 & & 1.00 & & 1.00 & & 1.00 & \\
\hline & $100-199$ & $0.75(0.58-0.97)$ & 0.03 & $0.75(0.58-0.97)$ & 0.03 & $0.78(0.61-1.01)$ & 0.06 & $0.79(0.61-1.03)$ & 0.08 \\
\hline & $200-299$ & $0.54(0.39-0.75)$ & 0.00 & $0.54(0.39-0.75)$ & 0.00 & $0.62(0.44-0.87)$ & 0.01 & $0.63(0.45-0.88)$ & 0.01 \\
\hline & $\geq 300$ & $0.50(0.34-0.76)$ & 0.00 & $0.51(0.34-0.77)$ & 0.00 & $0.61(0.40-0.92)$ & 0.02 & $0.62(0.41-0.94)$ & 0.03 \\
\hline \multirow{4}{*}{ Male } & $<100$ & 1.00 & & 1.00 & & 1.00 & & 1.00 & \\
\hline & $100-199$ & $0.83(0.56-1.23)$ & 0.34 & $0.82(0.55-1.22)$ & 0.33 & $0.84(0.56-1.25)$ & 0.38 & $0.84(0.56-1.25)$ & 0.39 \\
\hline & $200-299$ & $0.55(0.34-0.91)$ & 0.02 & $0.55(0.34-0.91)$ & 0.02 & $0.63(0.38-1.04)$ & 0.07 & $0.63(0.38-1.04)$ & 0.07 \\
\hline & $>300$ & $0.67(0.37-1.20)$ & 0.18 & $0.68(0.38-1.21)$ & 0.19 & $0.84(0.47-1.52)$ & 0.57 & $0.85(0.47-1.53)$ & 0.58 \\
\hline \multirow{4}{*}{ Female } & $<100$ & 1.00 & & 1.00 & & 1.00 & & 1.00 & \\
\hline & $100-199$ & $0.71(0.51-0.98)$ & 0.04 & $0.71(0.51-0.98)$ & 0.04 & $0.75(0.54-1.05)$ & 0.09 & $0.77(0.55-1.07)$ & 0.12 \\
\hline & $200-299$ & $0.54(0.35-0.83)$ & 0.01 & $0.54(0.35-0.84)$ & 0.01 & $0.62(0.40-0.97)$ & 0.04 & $0.63(0.40-0.98)$ & 0.04 \\
\hline & $\geq 300$ & $0.39(0.22-0.70)$ & 0.00 & $0.40(0.22-0.70)$ & 0.00 & $0.46(0.25-0.82)$ & 0.01 & $0.47(0.26-0.85)$ & 0.01 \\
\hline
\end{tabular}

${ }^{a}$ Adjusted for gender, age (continuous variable), education, and profession. ${ }^{\mathrm{b}}$ Additionally adjusted for hypertension. ${ }^{\mathrm{c}}$ Additionally adjusted for BMI, waist circumference, FBG, OTGG-2h, HbAlc, TC, LDL-C, and UA. ${ }^{\mathrm{d}}$ Additionally adjusted for TSH and TGAb.

TABLE 3: Effect of urinary iodine concentration on thyroid nodule according to the iodine nutritional status evaluation criteria of the WHO.

\begin{tabular}{|c|c|c|c|c|c|c|c|c|c|}
\hline \multirow{2}{*}{ Group } & \multirow{2}{*}{$\mathrm{UIC}\left(\mu \mathrm{g} \mathrm{l}^{-1}\right)$} & \multicolumn{2}{|l|}{ Model $1^{\mathrm{a}}$} & \multicolumn{2}{|l|}{ Model $2^{\mathrm{b}}$} & \multicolumn{2}{|l|}{ Model $3^{c}$} & \multicolumn{2}{|l|}{ Model $4^{\mathrm{d}}$} \\
\hline & & OR $(95 \% \mathrm{CI})$ & $p$ & OR $(95 \% \mathrm{CI})$ & $p$ & OR (95\% CI) & $p$ & OR (95\% CI) & $p$ \\
\hline \multirow{6}{*}{ All } & $<100$ & 1.00 & & 1.00 & & 1.00 & & 1.00 & \\
\hline & $100-199$ & $0.75(0.58-0.97)$ & 0.03 & $0.75(0.58-0.97)$ & 0.03 & $0.78(0.61-1.01)$ & 0.06 & $0.79(0.61-1.03)$ & 0.08 \\
\hline & $200-299$ & $0.54(0.39-0.75)$ & 0.00 & $0.54(0.39-0.75)$ & 0.00 & $0.62(0.44-0.87)$ & 0.01 & $0.62(0.45-0.87)$ & 0.01 \\
\hline & $300-399$ & $0.43(0.24-0.76)$ & 0.00 & $0.43(0.24-0.76)$ & 0.00 & $0.52(0.29-0.92)$ & 0.03 & $0.53(0.30-0.94)$ & 0.03 \\
\hline & $400-499$ & $0.42(0.18-1.00)$ & 0.05 & $0.42(0.18-1.00)$ & 0.05 & $0.52(0.21-1.25)$ & 0.14 & $0.52(0.22-1.26)$ & 0.15 \\
\hline & $\geq 500$ & $0.73(0.39-1.36)$ & 0.32 & $0.73(0.39-1.37)$ & 0.33 & $0.85(0.45-1.60)$ & 0.61 & $0.88(0.47-1.67)$ & 0.71 \\
\hline \multirow{6}{*}{ Male } & $<100$ & & & & & & & & \\
\hline & $100-199$ & $0.83(0.56-1.23)$ & 0.34 & $0.82(0.55-1.22)$ & 0.33 & $0.84(0.56-1.25)$ & 0.39 & $0.84(0.56-1.25)$ & 0.39 \\
\hline & 200-299 & $0.55(0.34-0.91)$ & 0.02 & $0.55(0.34-0.91)$ & 0.02 & $0.63(0.38-1.04)$ & 0.07 & $0.63(0.38-1.05)$ & 0.07 \\
\hline & $300-399$ & $0.57(0.26-1.26)$ & 0.16 & $0.57(0.26-1.26)$ & 0.17 & $0.74(0.33-1.65)$ & 0.46 & $0.74(0.33-1.66)$ & 0.47 \\
\hline & $400-499$ & $0.31(0.07-1.34)$ & 0.12 & $0.31(0.07-1.36)$ & 0.12 & $0.39(0.09-1.74)$ & 0.22 & $0.39(0.09-1.73)$ & 0.22 \\
\hline & $\geq 500$ & $1.29(0.55-3.01)$ & 0.56 & $1.31(0.56-3.05)$ & 0.53 & $1.48(0.63-3.48)$ & 0.37 & $1.50(0.64-3.54)$ & 0.35 \\
\hline \multirow{6}{*}{ Female } & $<100$ & & & & & & & & \\
\hline & $100-199$ & $0.71(0.51-0.98)$ & 0.04 & $0.71(0.51-0.98)$ & 0.04 & $0.75(0.54-1.05)$ & 0.09 & $0.77(0.55-1.07)$ & 0.12 \\
\hline & $200-299$ & $0.54(0.35-0.83)$ & 0.01 & $0.54(0.35-0.84)$ & 0.01 & $0.62(0.40-0.97)$ & 0.04 & $0.63(0.40-0.98)$ & 0.04 \\
\hline & $300-399$ & $0.33(0.15-0.76)$ & 0.01 & $0.34(0.15-0.76)$ & 0.01 & $0.38(0.16-0.86)$ & 0.02 & $0.39(0.17-0.89)$ & 0.03 \\
\hline & $400-499$ & $0.52(0.18-1.54)$ & 0.24 & $0.52(0.17-1.54)$ & 0.24 & $0.63(0.21-1.88)$ & 0.40 & $0.63(0.21-1.90)$ & 0.41 \\
\hline & $\geq 500$ & $0.42(0.16-1.10)$ & 0.08 & $0.42(0.16-1.11)$ & 0.08 & $0.50(0.19-1.32)$ & 0.16 & $0.53(0.20-1.39)$ & 0.20 \\
\hline
\end{tabular}

${ }^{\mathrm{a}}$ Adjusted for gender, age (continuous variable), education, and profession. ${ }^{\mathrm{b}}$ Additionally adjusted for hypertension. ${ }^{\mathrm{c}}$ Additionally adjusted for BMI, waist circumference, FBG, OTGG-2h, HbA1c, TC, LDL-C, and UA. ${ }^{\mathrm{d}}$ Additionally adjusted for TSH and TGAb.

TABLE 4: Effect of iodized salt intake on thyroid nodule.

\begin{tabular}{|c|c|c|c|c|c|c|c|c|c|}
\hline \multirow{2}{*}{ Group } & \multirow{2}{*}{ Iodized salt } & \multicolumn{2}{|l|}{ Model $1^{\mathrm{a}}$} & \multicolumn{2}{|c|}{ Model $2^{b}$} & \multicolumn{2}{|l|}{ Model $3^{c}$} & \multicolumn{2}{|l|}{ Model $4^{\mathrm{d}}$} \\
\hline & & OR $(95 \% \mathrm{CI})$ & $p$ & OR $(95 \% \mathrm{CI})$ & $p$ & OR $(95 \% \mathrm{CI})$ & $p$ & OR $(95 \% \mathrm{CI})$ & $p$ \\
\hline \multirow{2}{*}{ All } & No & 1.00 & & 1.00 & & 1.00 & & 1.00 & \\
\hline & Yes & $0.25(0.19-0.31)$ & 0.00 & $0.25(0.19-0.31)$ & 0.00 & $0.29(0.22-0.37)$ & 0.00 & $0.29(0.23-0.37)$ & 0.00 \\
\hline \multirow{2}{*}{ Male } & No & 1.00 & & 1.00 & & 1.00 & & 1.00 & \\
\hline & Yes & $0.23(0.16-0.32)$ & 0.00 & $0.23(0.16-0.33)$ & 0.00 & $0.27(0.19-0.38)$ & 0.00 & $0.27(0.19-0.39)$ & 0.00 \\
\hline \multirow{2}{*}{ Female } & $\mathrm{No}$ & 1.00 & & 1.00 & & 1.00 & & 1.00 & \\
\hline & Yes & $0.26(0.19-0.36)$ & 0.00 & $0.26(0.19-0.35)$ & 0.00 & $0.30(0.22-0.42)$ & 0.00 & $0.31(0.22-0.43)$ & 0.00 \\
\hline
\end{tabular}

${ }^{\mathrm{a}}$ Adjusted for gender, age (continuous variable), education, and profession. ${ }^{\mathrm{b}}$ Additionally adjusted for hypertension. ${ }^{\mathrm{c}}$ Additionally adjusted for BMI, waist

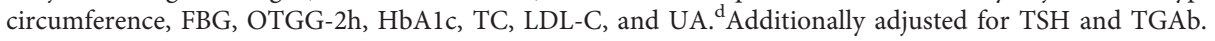

no significant association were found between excessive iodine intake and thyroid nodules with controlled confound factors. In this study, we subdivided excessive iodine intake into $300-399,400-499$, and $\geq 500 \mu \mathrm{gl}^{-1}$ groups to explore this association, and we found that the risk of thyroid nodules was not significantly different when comparing low 
UIC with higher UIC which was greater than $400 \mu \mathrm{g}{ }^{-1}$ after adjusted confounder. It means the risk of thyroid nodules may increase when UIC was $>400 \mu \mathrm{gl}^{-1}$. This finding is similar to the study conducted in Shanghai [30] which borders Zhejiang Province. However, the relatively small sample size of subjects who had UIC $>400 \mu \mathrm{g} \mathrm{l}^{-1}$ may be a limitation to fully demonstrate this association. Thus, further studies were needed to provide direct evidence of whether excessive iodine intake increases the risk of thyroid nodules and precisely define the threshold of excessive iodine intake.

Some limitations of this study are as follows. Firstly, we enrolled insufficient subjects who were exposed to excessive iodine; therefore, there was not enough power to fully demonstrate the association between thyroid nodules and high UIC. Secondly, our study belongs to cross-section studies, which could not clarify whether the occurrence of thyroid nodules cause reduction in UIC or the low UIC leads to increase the risk of thyroid nodules. Thus, observational studies with focuses on subjects with high iodine exposure are warranted in future.

\section{Conclusions}

In summary, our study revealed the association between iodine nutrition and the risk of thyroid nodules. The relationship between UIC and the risk of thyroid nodules is U-shaped. Consumption of noniodized salt is an independent risk factor of thyroid nodules.

\section{Data Availability}

The data belong to the funders and are not available to the public in order to protect the patient privacy.

\section{Disclosure}

The funds had no role in the design, analysis, or writing of this article

\section{Conflicts of Interest}

The authors declare no conflicts of interest.

\section{Authors' Contributions}

Xiaoming Lou and Xiaofeng Wang contributed equally to this work.

\section{Acknowledgments}

This work was supported by the National Natural Science Foundation of China (81502786); Zhejiang Province Basic Public Welfare Research Project (LGF20H240001); and Zhejiang Province Medical and Technology Fund (2019KY053, 2020KY093, 2020KY514, and 2020KY516). The authors thank the staff of the Centre for Disease Control and Prevention in Hangzhou and Zhoushan in Zhejiang Province, China, who collected the samples and epidemiological data. The authors particularly thank all the participants and their families for their contributions and support.

\section{References}

[1] B. R. Haugen, "American thyroid association management guidelines for adult patients with thyroid nodules and differentiated thyroid cancer," Thyroid, vol. 26, no. 1, pp. 1-133, 2015.

[2] W. Weng, "A PRISMA-compliant systematic review and meta-analysis of the relationship between thyroid disease and different levels of iodine intake in mainland China," Medicine, vol. 96 , no. $25,2017$.

[3] L. Hegedüs, "The thyroid nodule," New England Journal of Medicine, vol. 351, no. 17, pp. 1764-1771, 2004.

[4] S. Guth, U. Theune, J. Aberle, A. Galach, and C. M. Bamberger, "Very high prevalence of thyroid nodules detected by high frequency (13 $\mathrm{MHz})$ ultrasound examination," European Journal of Clinical Investigation, vol. 39, no. 8, pp. 699-706, 2009.

[5] S. J. Mandel, "A 64-year-old woman with a thyroid nodule," Jama, vol. 292, no. 21, pp. 2632-2642, 2004.

[6] M. T. Rojeski and H. Gharib, "Nodular thyroid disease," New England Journal of Medicine, vol. 313, no. 7, pp. 428-436, 1985.

[7] H. Gharib, "Changing concepts in the diagnosis and management of thyroid nodules," Endocrinology and Metabolism Clinics of North America, vol. 26, no. 4, pp. 777-800, 1997.

[8] H. Jiang, "The prevalence of thyroid nodules and an analysis of related lifestyle factors in beijing communities," International Journal of Environmental Research and Public Health, vol. 13, no. 4, 2016.

[9] Z. Chen, W. Xu, Y. Huang et al., "Associations of noniodized salt and thyroid nodule among the Chinese population: a large cross-sectional study," The American Journal of Clinical Nutrition, vol. 98, no. 3, pp. 684-692, 2013.

[10] A. Carlé, A. Krejbjerg, and P. Laurberg, "Epidemiology of nodular goitre. Influence of iodine intake," Best Practice \& Research Clinical Endocrinology \& Metabolism, vol. 28, no. 4, pp. 465-479, 2014.

[11] O. Province, Zhejiang Census Data, Zhejiang Gongshang University Press, Hangzhou, Zhejiang, 2010.

[12] S. Funaki, N. Umehara, H. Mezawa et al., "Ultrasonographic assessment of fetal thyroid in Japan: thyroid circumference and distal femoral and proximal tibial ossification," Journal of Medical Ultrasonics, vol. 1, 2020.

[13] WHO/UNICEF/ICCIDD, Assessment of Iodine Deficiency Disorders and Monitoring Their Elimination: A Guide for Program Managers, WHO, Geneva, Switerzland, 2007.

[14] Y. Li, D. Teng, J. Ba et al., "Efficacy and safety of long-term universal salt iodization on thyroid disorders: epidemiological evidence from 31 provinces of mainland China," Thyroid, vol. 30, no. 4, pp. 568-579, 2020.

[15] Y. Li, D. Teng, X. Shi et al., "Prevalence of diabetes recorded in mainland China using 2018 diagnostic criteria from the American Diabetes Association: national cross sectional study," BMJ, vol. 369, p. m997, 2020.

[16] K. Kiernan, "CONTRAST and ESTIMATE statements made easy: the LSMESTIMATE statement," SAS Global Forum, vol. 30, 2011.

[17] W. Zhao, "Prevalence of goiter and thyroid nodules before and after implementation of the universal salt iodization program in mainland China from 1985 to 2014: a systematic review and meta-analysis," PloS One, vol. 9, no. 10, 2014.

[18] J. Woestyn, M. Afschrift, K. Schelstraete, and A. Vermeulen, "Demonstration of nodules in the normal thyroid by 
echography," The British Journal of Radiology, vol. 58, no. 696, pp. 1179-1182, 1985.

[19] C. Reiners, K. Wegscheider, H. Schicha et al., "Prevalence of thyroid disorders in the working population of Germany: ultrasonography screening in 96,278 unselected employees," Thyroid, vol. 14, no. 11, pp. 926-932, 2004.

[20] H. W. Kang, J. H. No, J. H. Chung et al., "Prevalence, clinical and ultrasonographic characteristics of thyroid incidentalomas," Thyroid, vol. 14, no. 1, pp. 29-33, 2004.

[21] E. Tomimori, F. Pedrinola, H. Cavaliere, M. Knobel, and G. Medeiros-neto, "Prevalence of incidental thyroid disease in a relatively low iodine intake area," Thyroid, vol. 5, no. 4, pp. 273-276, 1995.

[22] .S. Jun, "Prevalence of thyroid nodules and its relationship with iodine status in shanghai:a population-based study," Biomedical and Environmental Sciences, vol. 29, no. 6, p. 398, 2016.

[23] L. Fan, L. Tan, Y. Chen et al., "Investigation on the factors that influence the prevalence of thyroid nodules in adults in Tianjin, China," Journal of Trace Elements in Medicine and Biology, vol. 50, pp. 537-542, 2018.

[24] B. Zou, "The prevalence of single and multiple thyroid nodules and its association with metabolic diseases in Chinese: a cross-sectional study," International Journal of Endocrinology, vol. 2020, 2020.

[25] S. Gaengler, X. D. Andrianou, A. Piciu et al., "Iodine status and thyroid nodules in females: a comparison of Cyprus and Romania," Public Health, vol. 143, pp. 37-43, 2017.

[26] X. Yu, C. Fan, Z. Shan et al., "A five-year follow-up study of goiter and thyroid nodules in three regions with different iodine intakes in China," Journal of Endocrinological Investigation, vol. 31, no. 3, pp. 243-250, 2008.

[27] P. Laurberg, I. B. Pedersen, N. Knudsen, L. Ovesen, and S. Andersen, "Environmental iodine intake affects the type of nonmalignant thyroid disease," Thyroid, vol. 11, no. 5, pp. 457-469, 2001.

[28] K. Krohn, D. Führer, Y. Bayer et al., "Molecular pathogenesis of euthyroid and toxic multinodular goiter," Endocrine Reviews, vol. 26, no. 4, pp. 504-524, 2005.

[29] G. Q. Ding, "Assessment of dietary iodine intakes by 3-day dietary records in Zhejiang residents," Acta Nutrimenta Sinica, vol. 36, no. 6, pp. 553-558, 2014.

[30] J. Song, S. R Zou, C. Y Guo et al., "Prevalence of thyroid nodules and its relationship with iodine status in Shanghai: a population-based study," Biomedical and Environmental Sciences: BES, vol. 29, no. 6, pp. 398-407, 2016.

[31] I. Gunnarsdottir and L. Dahl, "Iodine intake in human nutrition: a systematic literature review," Food \& Nutrition Research, vol. 56, no. 4, 2012.

[32] H. F. Zhu, "[Prevalence of thyroid nodules and influencing factors among employees of a company in Qingdao," Chinese Journal of Preventive Medicine, vol. 46, no. 3, p. 228, 2012. 